\title{
Identifying Entrustable Professional Activities for Internal Medicine Residents in Ambulatory Continuity Practice
}

\author{
Christine Soran, $M D, M P H^{7}{ }^{10}$, Ryan Laponis, MD, MSci',3, Sarah Summerville, $\mathrm{MD}^{2}$, \\ Vanessa Thompson, $\mathrm{MD}^{1,3}$, Abigail Eastburn, $\mathrm{MD}^{4}$, Patricia O'Sullivan, EdD ${ }^{5,6,7}$, and \\ Katherine A. Julian, $\mathrm{MD}^{1,3}$
}

\begin{abstract}
'Division of General Internal Medicine, Zuckerberg San Francisco General Hospital , University of California San Francisco , San Francisco , CA , USA; ${ }^{2}$ Division of General Internal Medicine, University of California San Francisco, San Francisco , CA , USA; ${ }^{3}$ Internal Medicine Residency Program , University of California San Francisco, San Francisco , CA , USA; ' Division of General Internal Medicine, San Francisco Veterans Affairs Medical Center , University of California San Francisco, San Francisco , CA , USA; ${ }^{5}$ Department of Medicine, University of California San Francisco , San Francisco , CA , USA; ${ }^{6}$ Department of Surgery, University of California San Francisco, San Francisco, CA , USA; ${ }^{7}$ Research and Development in Medical Education, University of California San Francisco, San Francisco, CA , USA.
\end{abstract}

J Gen Intern Med 35(6):1917-9

DOI: $10.1007 / \mathrm{s} 11606-019-05430-8$

(c) Society of General Internal Medicine 2019

\section{INTRODUCTION}

Medical care is increasingly provided in the ambulatory setting. Internal medicine (IM) residency training programs must assess residents' trajectory to independently provide quality care in ambulatory continuity practice.

Entrustable professional activities (EPAs) are measurable, discrete tasks used for competency-based assessment. This study aimed to identify EPAs for IM residents applicable to the ambulatory continuity setting overcoming others' failure to achieve consensus. ${ }^{1-3}$

\section{METHODS}

Three authors (C.S., K.J., R.L.) compiled a list of 177 potential EPAs from a literature review. ${ }^{1,3-5}$ The study team eliminated EPAs irrelevant to ambulatory IM, reducing the list to 50 EPAs. A group of medical educators combined redundant EPAs and identified gaps finalizing 20 candidate EPAs. Two study authors (C.S., R.L.) graded each EPA using the EQual rubric, an instrument with 14 categories scored on a scale of 15 to evaluate EPA consistency. ${ }^{6}$ The team re-evaluated EPAs scoring less than 4 in any category. Through the revision process, the team eliminated four EPAs and revised five, resulting in sixteen EPAs.

Participants in the study were IM physician educators from one of three settings: a university-based clinic, a VA clinic, or a safety net clinic. Using a Delphi technique, participants could

$\overline{\text { Preliminary findings from this paper were presented in a poster session at }}$ the Society of General Internal Medicine Annual Conference in Denver, Colorado, in April 2018.

Received August 16, 2019

Revised August 27, 2019

Accepted September 24, 2019

Published online October 21, 2019 complete two rounds of surveys via email. In the first round, participants rated level of importance of each EPA on a 5-point Likert scale ( $1=$ not at all important, $5=$ very important $)$ and in which year of training a resident is expected to be independent (PGY1-PGY3). Respondents could submit additional EPAs. In round 2, respondents received their response from

Table 1 Delphi Participant Characteristics

\begin{tabular}{|c|c|}
\hline & $N(\%)$ \\
\hline \multicolumn{2}{|l|}{ Title } \\
\hline Professor & $8(50)$ \\
\hline Associate professor & $4(25)$ \\
\hline Assistant professor & $3(19)$ \\
\hline Other & $1(6)$ \\
\hline \multicolumn{2}{|l|}{ Practice site } \\
\hline VA clinic & $5(31)$ \\
\hline University clinic & $8(50)$ \\
\hline County clinic & $3(19)$ \\
\hline \multicolumn{2}{|l|}{ Years precepting } \\
\hline $2-5$ & $2(13)$ \\
\hline $6-10$ & $5(31)$ \\
\hline $11-15$ & $2(13)$ \\
\hline $16-20$ & $3(19)$ \\
\hline $21-25$ & $2(13)$ \\
\hline$>25$ & $2(13)$ \\
\hline \multicolumn{2}{|c|}{ Half days of precepting per week on average throughout career } \\
\hline 1 & $8(50)$ \\
\hline 2 & $6(38)$ \\
\hline 3 & $1(6)$ \\
\hline 4 & $1(6)$ \\
\hline \multicolumn{2}{|c|}{ Years outpatient attending } \\
\hline $2-5$ & $2(13)$ \\
\hline $6-10$ & $4(25)$ \\
\hline $11-15$ & $3(19)$ \\
\hline $16-20$ & $3(19)$ \\
\hline $21-25$ & $2(13)$ \\
\hline$>25$ & $2(13)$ \\
\hline \multicolumn{2}{|l|}{ Scholarly publications } \\
\hline Yes & $15(94)$ \\
\hline No & $1(6)$ \\
\hline \multicolumn{2}{|c|}{ Scholarly work on medical education } \\
\hline Yes & $6(38)$ \\
\hline No & $10(63)$ \\
\hline \multicolumn{2}{|c|}{ Teaching Scholars Program graduate } \\
\hline Yes & $5(31)$ \\
\hline No & $11(69)$ \\
\hline \multicolumn{2}{|c|}{ Academy of Medical Educators member } \\
\hline Yes & $5(31)$ \\
\hline No & $11(69)$ \\
\hline
\end{tabular}




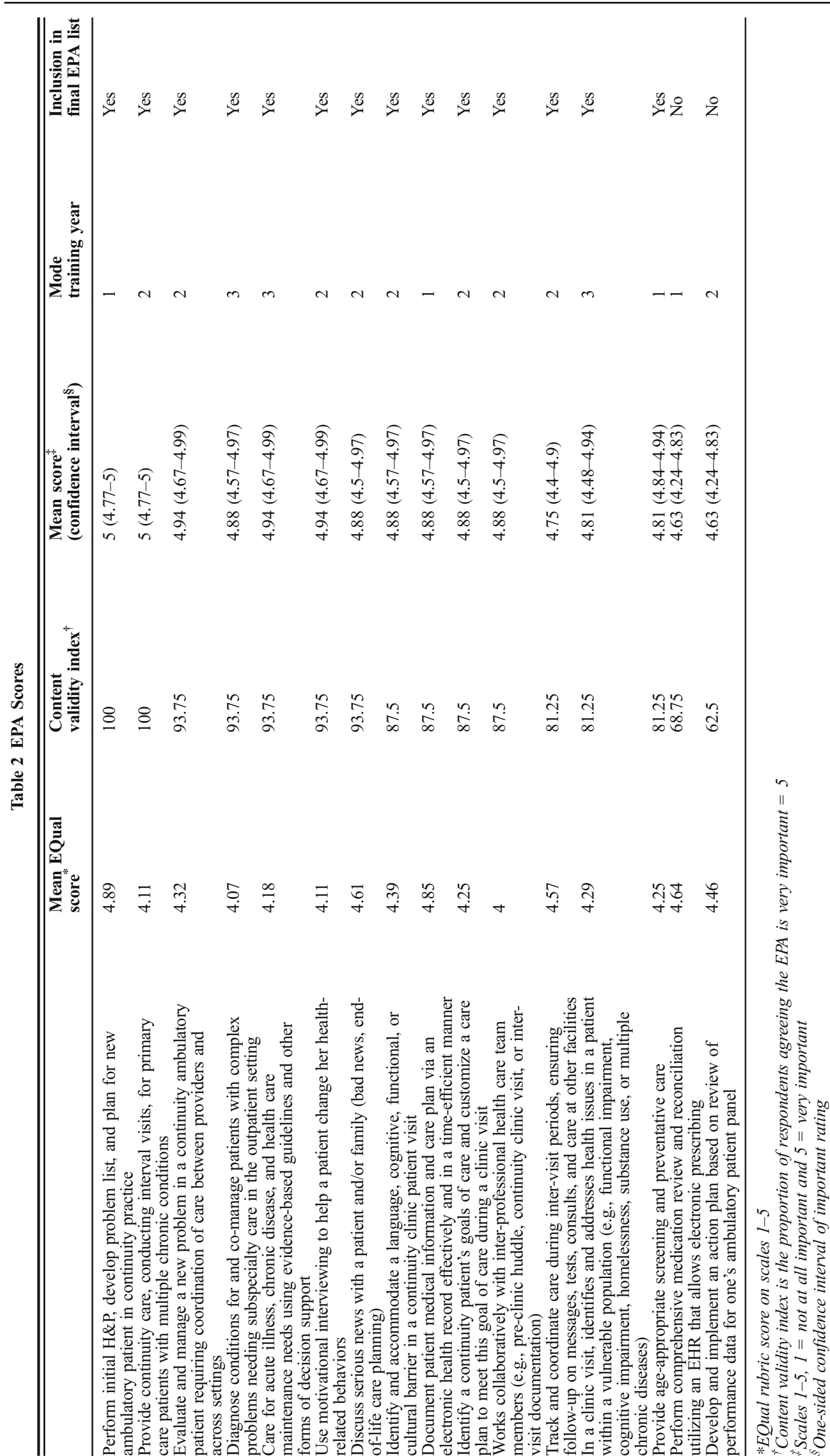


round 1 and the distribution of responses from all participants and asked if they would like to change any of their initial ratings.

A mean score and a content validity index (CVI) for each EPA were calculated from responses to the second-round survey. The CVI was the proportion of respondents scoring the EPA "very important" (score 5). EPAs with a content validity index $>80 \%$ were included in the final core list of EPAs. Asymmetric 95\% confidence intervals were calculated to address skewness in the responses and to ensure that the confidence interval included nothing lower than 4 which was the lower bound established. The institutional review board gave this study exempt status.

\section{RESULTS}

The characteristics of Delphi participants are presented in Table 1 . Of the 76 faculty educators invited to participate, 20 participants completed round 1 and sixteen participated in both rounds. Half of participants were full professors and all three clinic sites were represented. Experience precepting residents in continuity clinic ranged from 5 to 30 years.

Table 2 shows the EQual rubric scores, CVI, mean importance score, $95 \%$ asymmetric confidence interval, and mode of training year for assessment. The EQual rubric scores ranged from 4 to 4.89 . Two EPAs had $100 \%$ agreement as "very important," five EPAs had $>90 \%$ agreement, and fourteen out of sixteen exceeded the $80 \%$ agreement threshold. All EPAs had a mean importance rating greater than 4 and no confidence interval crossed 4 . The mode year of assessment for four of the EPAs was PGY-1, nine in PGY-2, and three in PGY-3.

\section{DISCUSSION}

Our study found 14 EPAs important for IM ambulatory continuity medicine. This final list represents a foundation of EPAs that can be applied in ambulatory IM training. Educators had a strong agreement on the importance of each included EPA supporting the process of defining EPAs through literature review, EQual rubric scoring, and revision. The two eliminated EPAs had wide confidence intervals reflecting variation in responses among the participants. The experience of the participants in this study suggests their insights are likely to capture appropriate tasks for ambulatory practice. The EQual rubric provided a helpful tool for refinement of EPAs to meet a standard definition early in the process. This study shows a process for defining EPAs for the ambulatory continuity component of IM training that could be reproduced for other specialties or practice settings.

Limitations of our study include data from a single institution. Additionally, the foundation of our EPA list was based on literature review in a nascent field. While we allowed participants to comment on gaps in our list, there may be other relevant EPAs not included.

Corresponding Author: Christine Soran, MD, MPH; Division of General Internal Medicine, Zuckerberg San Francisco General Hospital University of California San Francisco, San Francisco, CA , USA (e-mail: Christine.soran@ucsf.edu).

\section{Compliance with Ethical Standards:}

Conflict of Interest: The authors declare that they do not have a conflict of interest.

\section{REFERENCES}

1. Hauer KE, Kohlwes $\mathbf{J}$, Cornett $\mathbf{P}$, et al. Identifying entrustable professional activities in internal medicine training. $J$ Grad Med Ed. 2013:5(1):54-59.

2. Post JA, Wittich CM, Thomas KG, et al. Rating the quality of entrustable professional activities: Content validation and associations with the clinical context. J Gen Intern Med. 2016;31(5):518-523.

3. Caverzagie KJ, Cooney TG, Hemmer PA, Berkowitz L. The development of entrustable professional activities for internal medicine residency training: A report from the education redesign committee of the alliance for academic internal medicine. Academic Med. 2015;90(4):479-484

4. Shaughnessy AF, Sparks J, Cohen-Osher M, Goodell KH, Sawin GL, Gravel Jr J. Entrustable professional activities in family medicine. J Grad Med Ed. 2013;5(1):112-118.

5. Chang A, Bowen JL, Buranosky RA, et al. Transforming primary care training-patient-centered medical home entrustable professional activities for internal medicine residents. Journal of general internal medicine. 2013;28(6):801-809.

6. Taylor DR, Park YS, Egan R, et al. EQual, a novel rubric to evaluate entrustable professional activities for quality and structure. Academic Medicine. 2017;92(11S):S117

Publisher's Note Springer Nature remains neutral with regard to jurisdictional claims in published maps and institutional affiliations. 